\title{
Studies of Isolated Fetal Mouse Hearts in Organ Culture
}

\author{
EVIDENCE FOR A DIRECT EFFECT OF TRIIODOTHYRONINE IN \\ ENHANCING CARDIAC RESPONSIVENESS TO NOREPINEPHRINE
}

\author{
Kern Wildenthal with the technical assistance of Jacouline R. WAKELAND \\ From the Pauline and Adolph Weinberger Laboratory for Cardiopulmonary \\ Research, Departments of Physiology and Internal Medicine, University of \\ Texas Southwestern Medical School at Dallas, Dallas, Texas 752.35
}

\begin{abstract}
A B S T R A C T Definitive confirmation or denial of the 1ypothesis that thyrotoxic hearts are supersensitive to catecholamines has been difficult to obtain. largely because secondary alterations in neural and humoral factors that occur after thyroid administration in vivo may obscure the primary changes incluced by the hormone on the myocardium itself. To study the direct action of thyroid hormone apart from secondary factors, thyrotoxicosis should be induced in isolated hearts in vitro, but the slow onset of thyroid action plus the rapid deterioration of conventional in vitro preparations have precluded such experiments.
\end{abstract}

Recenly a method was developed for maintaining intact. spontaneously-beating hearts from late-fetal mice in organ culture for several weeks. When $5 \times 10^{-5}$ to $5 \times 10^{-6}$. 1 L-triiolothyronine is adcled to the culture medium arrhythmias and or tachycardia gradually appear, just as in thyrotoxicosis in vivo. Accordingly. these "thyrotoxic" hearts were used in the present experiments to test for altered responsiveness to norepinephrine. Dose-response curves to norepinephrine were identical for hearts maintained for $3 \mathrm{hr}$ in triiodothyronine-treated or control medium. After 2 days, however, the curve was shifted to the left in triiodothyroninetreated hearts. Thus, $10^{-\infty}$ is norepinephrine increased the atrial rate by $20 \pm 6.1$ ( $\mathrm{SEM}$ ) beats/min in hearts exposed to $5 \times 10^{-6}$ M triiodothyronine and by $1 \pm 3.0$ in control hearts $(P<0.02) ; 10^{-\mathbf{7}} \mathrm{M}$ norepinephrine raised the rate by $79 \pm 22.3$ in treated hearts vs. $17 \pm 9.8$ in controls $(P<0.05)$. At maximal doses $\left(10^{-6} \mathrm{M}\right.$ norepinephrine), increases were identical. In addition, nor-

Dr. Wildenthal is the recipient of a Research Career Development Award from the National Heart and I.ung Institute.

Receized for publication 6 April 1972 and in reised form o June 19ז?. epinephrine $\left(10^{-5}-10^{-6} \mathrm{~m}\right)$ induced arrhythmias in $56 \%$ of treated hearts rs. $14 \%$ of controls $(P<0.01)$. Thus. in a precisely controlled environment free of differences in neural and humoral factors, triiodothyronine can act directly on the fetal mouse heart to enhance sensitivity to norepinephrine.

\section{INTRODUCTION}

The tachycardia that occurs in hyperthyroidism has been thought in the past to be mediated by one or more of three separate mechanisms: (a) a direct effect of thyroid hormones on the heart, (b) an increase in simpathoadrenal activity, and $(c)$ an increased sensitivity of the thyrotoxic heart cell to catecholamines. Although there is no unanimity of opinion (1), the current consensus seems to be similar to the view of Levey (2), who concluded from a review of the literature that a direct chronotropic action of thyroid hormone on the heart definitely occurs, that altered amounts of catecholamines reach the myocardial cells in thyrotoxicosis, but that the best currently available clata suggest that the sensitivity of the heart to catecholamines is not enhanced (3-8).

One unavoidable difficulty in making precisely controlled studies of the myocardial effects of thyroid hormones by conventional means has been that the onset of action of the hormones is slow (9-11). Because conventional preparations for studying the heart in vitro function well for only a few hours, the preparations become unstable before thyroid effects are apparent. Therefore, to study hyperthyroid myocardium it has been necessary to induce thyrotoxicosis in the intact animal, where secondary alterations in neural activity. circulating hormones, and blood substrate levels are impossible to control completely. These seconclary 
changes may obscure or confuse the intrinsic effects of the thyroid hormone on the myocardial cell.

To provide a means for studying the myocardium for long periods under precisely controlled conditions in vitro, a system has recently been developed for maintaining intact, spontaneously-beating hearts from late-fetal mice in organ culture (12). Beating rates vary from heart to heart, but each heart maintains a reasonably stable rate for several days or weeks under control conditions (12). When thyroxine or triiodothyronine is added to the culture medium the spontaneous beating rate gradually increases and arrhythmias begin to appear over a period of 2 or more days, as in vivo (13). The isolated hearts are denervated, of course, and they rapidly become depleted of endogenous catecholamines so that by $36 \mathrm{hr}$ after explanation they contain no demonstrable amounts of norepinephrine or epinephrine (i.e. $<0.1 \mu \mathrm{g} / \mathrm{g}$ ) in the presence or absence of thyroid hormone ( $\mathrm{P}$. A. Shore and $\mathrm{K}$. Wildenthal, unpublished data). Accordingly, it seemed that fetal mouse hearts in long-term organ culture might provide a means for testing the responsiveness to catecholamines of hearts made "thyrotoxic" in an isolated, controlled environment, free of the complex secondary events that occur when hyperthyroidism is induced in vivo.

\section{METHODS}

Hearts from 18-20 day fetal mice were prepared and maintained in organ culture by techniques described previously (12). Briefly, hearts were removed aseptically from the fetuses, the pericardia and vessels were carefully dissected away, intracavitary blood and body fluids were gently washed away, and the hearts were placed on stainless steel grids at the liquid-air interface of shallow culture chambers. The hearts at explantation weighed $3-5 \mathrm{mg}$ and measured $\frac{1}{2}-2$ $\mathrm{mm}$ in their major diameters. 66 hearts were cultured as completely intact organs, so that atrial pacemaker activity was dominant. In 45 others, the atria were removed so that spontaneous ventricular rates and rhythm could be observed.

The standard medium used in all experiments was "medium 199" (14), supplemented with $500 \mu$ moles/liter sodium octanoate and $50 \mu \mathrm{g} / \mathrm{ml}$ regular insulin. The atmosphere was $95 \% \mathrm{O}_{2}+5 \% \mathrm{CO}_{2}$, which resulted in a $\mathrm{pH}$ in the medium of 7.35-7.45. For thyroid-treated hearts, littermates of the control hearts were maintained under identical conditions in the presence of the above medium supplemented with $5 \times 10^{-\pi}$ is or $5 \times 10^{-6}$ is L-triiodothyronine (Mann Research Labs., Inc., New York). The hormone was dissolved in $1 \mathrm{ml}$ of $0.1 \mathrm{~N} \mathrm{NaH}$ before being added to the medium, and an equal volume of $\mathrm{NaOH}$ was added to the control medium.

The hearts in their culture chambers were incubated at $37.2 \pm 0.5^{\circ} \mathrm{C}$. After $2 \frac{1}{2}-3 \mathrm{hr} 24$ of the chambers were transferred to a controlled-temperature water bath in room air, where experiments were performed. The remaining hearts were incubated without interruption for $48 \mathrm{hr}$, when their chambers were transferred to the water bath. Previous experiments have established that the rate, rhythm, and amplitude of contraction of cultured hearts of all ages remain constant in the bath for at least $20 \mathrm{~min}$ (15). In the

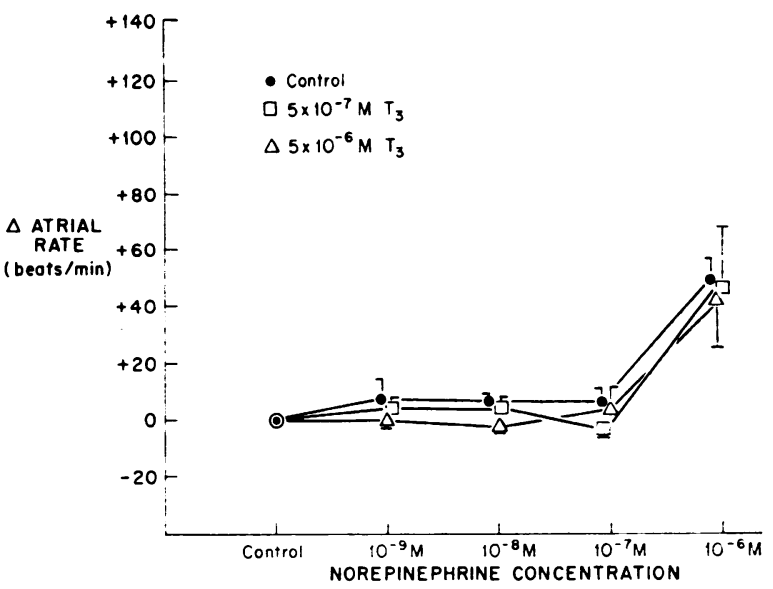

FIGLRE 1 Dose-response curve of isolated hearts maintained for $3 \mathrm{hr}$ in the presence or absence of triiodothyronine $\left(T_{3}\right)$, relating changes in spontaneous atrial rates to the concentration of norepinephrine. Vertical bars represent \pm 1 SEM. There were no significant differences at any point. See Table I for absolute values of heart rate.

present experiment, all observations were made within a $10 \mathrm{~min}$ period.

Base line beating rates and rhythms were observed through a dissecting microscope and recorded. Then, the original medium was replaced with one containing $10^{-9} \mathrm{M}$ L-norepinephrine bitartrate. After a 1-min stabilization period the rate and rhythm were again measured over a 15-30 sec period. The medium was then replaced consecutively by ones with $10^{-8} \mathrm{M}, 10^{-7} \mathrm{M}, 10^{-6} \mathrm{M}$, and $10^{-5} \mathrm{M}$ norepinephrine, and rates were counted after 1-min stabilization intervals in each instance. Significant arrhythmias were considered to be present if two or more irregular atrial or ventricular contractions occurred or if there were recurrent brief periods of asystole; atrial fibrillation was never observed. Tachycardia in response to norepinephrine always developed gradually and progressively over a period of several seconds until a steady state was reached, which suggests that the faster rates caused by the drug were in no instances due to the onset of a regular paroxysmal tachycardia from an aberrant focus. Rates were recorded to the nearest multiple of 10 beats $/ \mathrm{min}$. The $10^{-5} \mathrm{M}$ dose caused little or no additional increase in rate in most hearts and bradyarrhythmias in some, so that the mean beating rate actually fell slightly with that dose in the present study. Accordingly, $10^{-6}$ ir was considered the "maximal" dose.

The media to which norepinephrine was added were identical to the culture media except that $\mathrm{NaHCO}_{3}$ was added in amounts to yield a $\mathrm{pH}$ of 7.4 in room air rather than in the $5 \%$ CO.s atmosphere. All media were prewarmed to $37-38^{\circ} \mathrm{C}$.

To evaluate responsiveness to indirectly-acting sympathomimetic amines, and thus to test the degrce of functional denervation of the hearts, additional experiments were made using tyramine. Although there is some evidence to the contrary (16), that drug is generally believed to act primarily by releasing endogenous stores of norepinephrine (17). Accordingly, tyramine $\mathrm{HCl}$ was added to the media and its effects on hearts cultured for $2 \frac{1}{2}-3 \mathrm{hr}$ or for 2 days in the presence or absence of $10^{-5} \mathrm{M}$ triiodothyronine were tested in the same manner as were norepinephrine's effects. 
TABLE I

Spontaneous Atrial Rates of Isolated Fetal Mouse Hearts Maintained for $3 \mathrm{hr}$ in the Presence or Absence of Triiodothyronine, before and after Exposure to Norepinephrine

\begin{tabular}{|c|c|c|c|c|c|c|c|c|c|}
\hline Number & $\begin{array}{l}\text { Control } \\
\text { rate }\end{array}$ & $\begin{array}{l}\text { Rate after } \\
10^{-9} \mathrm{M} \mathrm{NE}\end{array}$ & $\begin{array}{l}\text { Change from } \\
\text { control }\end{array}$ & $\begin{array}{l}\text { Rate after } \\
10^{-8} \mathrm{M} \mathrm{NE}\end{array}$ & $\begin{array}{l}\text { Change from } \\
\text { control }\end{array}$ & $\begin{array}{l}\text { Rate after } \\
10^{-7} \mathrm{M} \mathrm{NE}\end{array}$ & $\begin{array}{l}\text { Change from } \\
\text { control }\end{array}$ & $\begin{array}{l}\text { Rate after } \\
10^{-6} \mathrm{M} \mathrm{NE}\end{array}$ & $\begin{array}{l}\text { Change from } \\
\text { control }\end{array}$ \\
\hline \multicolumn{10}{|c|}{ Hearts maintained in the absence of $T_{3}$} \\
\hline 1 & 250 & 300 & +50 & 250 & 0 & 250 & 0 & 290 & +40 \\
\hline 2 & 70 & 70 & 0 & 70 & 0 & 60 & -10 & 120 & +50 \\
\hline 3 & 140 & 140 & 0 & 150 & +10 & 140 & 0 & 200 & +60 \\
\hline 4 & 150 & 170 & +20 & 150 & 0 & 150 & 0 & 200 & +50 \\
\hline 5 & 130 & 120 & -10 & 140 & +10 & 140 & +10 & $150^{*}$ & +20 \\
\hline 6 & 120 & 120 & 0 & 130 & +10 & 130 & +10 & 160 & +40 \\
\hline 7 & 150 & 140 & -10 & 160 & +10 & 180 & +30 & $230^{*}$ & +80 \\
\hline Mean & 144 & 151 & +7 & 150 & +6 & 150 & +6 & 193 & +49 \\
\hline SD & 54.1 & 72.2 & 21.4 & 53.2 & 5.3 & 57.2 & 12.7 & 56.5 & 18.6 \\
\hline SE & 20.5 & 27.3 & 8.1 & 20.1 & 2.0 & 21.6 & 4.8 & 21.3 & 7.0 \\
\hline \multicolumn{10}{|c|}{ Hearts maintained in medium containing $5 \times 10^{-7} \mathrm{M} \mathrm{T}_{3}$} \\
\hline 1 & 240 & 240 & 0 & 260 & +20 & 240 & 0 & 250 & +10 \\
\hline 2 & 100 & 100 & 0 & 100 & 0 & 110 & +10 & 270 & +170 \\
\hline 3 & 190 & 200 & +10 & 190 & 0 & 190 & 0 & 250 & +60 \\
\hline 4 & 120 & 120 & 0 & 120 & 0 & 110 & -10 & 150 & +30 \\
\hline 5 & 160 & 160 & 0 & 170 & +10 & 160 & 0 & 190 & +30 \\
\hline 6 & 230 & 230 & 0 & 220 & -10 & 220 & -10 & 230 & 0 \\
\hline 7 & 60 & 80 & +20 & 70 & +10 & 50 & -10 & 80 & +20 \\
\hline Mean & 157 & 161 & +4 & 161 & +4 & 154 & -3 & 203 & +46 \\
\hline SD & 67.5 & 63.8 & 7.8 & 68.1 & 9.7 & 68.0 & 7.5 & 67.9 & 58.0 \\
\hline SE & 25.6 & 24.5 & 3.0 & 26.1 & 3.7 & 26.1 & 2.8 & 26.1 & 22.0 \\
\hline \multicolumn{10}{|c|}{ Hearts maintained in medium containing $5 \times 10^{-6} \mathrm{M} \mathrm{T}_{3}$} \\
\hline 1 & 220 & 220 & 0 & 220 & 0 & 290 & +70 & 350 & +130 \\
\hline 2 & 180 & 180 & 0 & 180 & 0 & 170 & -10 & 170 & -10 \\
\hline 3 & 130 & 130 & 0 & 120 & -10 & 120 & -10 & 140 & +10 \\
\hline 4 & 100 & 100 & 0 & 100 & 0 & 100 & 0 & 130 & +30 \\
\hline 5 & 120 & 110 & -10 & 110 & -10 & 120 & 0 & 130 & +10 \\
\hline 6 & 110 & 110 & 0 & 110 & 0 & 110 & 0 & 100 & -10 \\
\hline 7 & 250 & 270 & +20 & 250 & 0 & 240 & -10 & 340 & +90 \\
\hline 8 & 90 & 100 & +10 & 90 & 0 & 90 & 0 & 220 & +130 \\
\hline 9 & 150 & 150 & 0 & 150 & 0 & 150 & 0 & 160 & +10 \\
\hline 10 & 110 & 110 & 0 & 110 & 0 & 100 & -10 & 140 & +30 \\
\hline Mean & 146 & 148 & +2 & 144 & -2 & 149 & +3 & 188 & +42 \\
\hline SD & 54.0 & 58.1 & 7.9 & 55.0 & 4.2 & 66.7 & 24.1 & 88.5 & 55.4 \\
\hline $\mathrm{SE}$ & 17.1 & 18.4 & 2.5 & 17.4 & 1.3 & 21.1 & 7.6 & 28.0 & 17.2 \\
\hline
\end{tabular}

Abbreviations: NE, norepinephrine; $\mathrm{T}_{3}$, triiodothyronine.

* Arrhythmia present.

\section{RESULTS}

Brief $\left(2 \frac{1}{2}-3 h r\right)$ exposure to triiodothyronine. Before norepinephrine was given spontaneous beating rates varied from heart to heart in all groups, as is the rule in cultured hearts (12). The average rates were similar in control hearts and in hearts exposed for $2 \frac{1}{2}-3 \mathrm{hr}$ to triiodothyronine (Table I). With norepinephrine, all hearts developed tachycardia. The amount of change and the level of norepinephrine at which changes occurred were similar in each group
(Fig. 1). Also, there were no significant differences in the incidence of arrhythmias in the various groups, before or after norepinephrine (Table I).

High concentrations of tyramine $\left(10^{-4} \mathrm{M}\right)$ caused small but significant increases in the spontaneous atrial rate in both control and triiodothyronine-treated hearts. There were no differences in the responsiveness of the two groups (Fig. 2).

Prolonged (2 day) exposure to triiodothyronine. Spontaneous atrial rates before norepinephrine were 
TABLE II

Spontaneous Atrial Rates of Hearts Maintained for 2 Days in the Presence or Absence of Triiodothyronine, before and after Exposure to Norepinephrine

\begin{tabular}{|c|c|c|c|c|c|c|c|c|c|}
\hline Number & $\begin{array}{l}\text { Control } \\
\text { rate }\end{array}$ & $\begin{array}{l}\text { Rate after } \\
10^{\rightarrow} \text { M NE }\end{array}$ & $\begin{array}{l}\text { Change from } \\
\text { control }\end{array}$ & $\begin{array}{l}\text { Rate after } \\
10^{-8} \mathrm{M} \mathrm{NE}\end{array}$ & $\begin{array}{l}\text { Change from } \\
\text { control }\end{array}$ & $\begin{array}{l}\text { Rate after } \\
10^{-7} \text { M NE }\end{array}$ & $\begin{array}{l}\text { Change from } \\
\text { control }\end{array}$ & $\begin{array}{l}\text { Rate after } \\
10^{-6} \mathrm{M} \mathrm{NE}\end{array}$ & $\begin{array}{l}\text { Change from } \\
\text { control }\end{array}$ \\
\hline \multicolumn{10}{|c|}{ Hearts maintained in the absence of $T_{3}$} \\
\hline 1 & 130 & 130 & $\mathbf{0}$ & 120 & -10 & 110 & -20 & 320 & +190 \\
\hline 2 & 80 & 70 & -10 & 60 & -20 & 60 & -20 & 90 & +10 \\
\hline 3 & 270 & 270 & 0 & 280 & +10 & 370 & +100 & 460 & +190 \\
\hline 4 & 210 & 250 & +40 & 210 & 0 & 210 & 0 & $230^{*}$ & +20 \\
\hline 5 & 80 & 60 & -20 & 80 & 0 & 100 & +20 & 430 & +350 \\
\hline 6 & 120 & 120 & 0 & 130 & +10 & 150 & +30 & 400 & +280 \\
\hline 7 & 220 & 270 & +50 & 210 & -10 & 210 & -10 & 310 & +90 \\
\hline 8 & $90^{*}$ & $90^{*}$ & 0 & $90^{*}$ & 0 & $90^{*}$ & 0 & 140 & +50 \\
\hline 9 & 280 & 280 & 0 & 280 & 0 & 290 & +10 & 330 & +50 \\
\hline 10 & 90 & 90 & 0 & 90 & 0 & 130 & +40 & 160 & +70 \\
\hline 11 & 120 & 120 & 0 & 140 & +20 & 180 & +60 & 240 & +120 \\
\hline 12 & 40 & 40 & 0 & 30 & -10 & 30 & -10 & 130 & +90 \\
\hline 13 & 280 & 300 & +20 & 300 & +20 & 260 & -20 & 400 & +120 \\
\hline 14 & 60 & 60 & 0 & 60 & 0 & 120 & +60 & 200 & +140 \\
\hline Mean & 148 & 154 & +6 & 149 & +1 & 165 & +17 & 274 & +126 \\
\hline SD & 85.9 & 96.9 & 18.7 & 91.0 & 11.4 & 94.7 & 36.7 & 121.3 & 97.8 \\
\hline SE & 23.0 & 25.9 & 5.0 & 24.3 & 3.0 & 25.3 & 9.8 & 32.4 & 26.1 \\
\hline \multicolumn{10}{|c|}{ Hearts maintained in medium containing $5 \times 10^{-7} \mathrm{M} \mathrm{T}_{3}$} \\
\hline 1 & 130 & 120 & -10 & 120 & -10 & 120 & -10 & $190^{*}$ & +60 \\
\hline 2 & 70 & 70 & 0 & 70 & 0 & 70 & 0 & 220 & +150 \\
\hline 3 & 50 & 40 & -10 & 50 & 0 & 40 & -10 & 320 & +270 \\
\hline 4 & 110 & 100 & -10 & $110^{*}$ & 0 & 210 & +100 & 310 & +200 \\
\hline 5 & 100 & 90 & -10 & $100^{*}$ & 0 & $120^{*}$ & +20 & $130^{*}$ & +30 \\
\hline 6 & 180 & 180 & 0 & 220 & +40 & 170 & -10 & 250 & +70 \\
\hline 7 & 60 & 60 & 0 & 60 & 0 & $60^{*}$ & 0 & 110 & +50 \\
\hline 8 & 80 & 70 & -10 & 90 & +10 & 140 & +60 & 180 & +100 \\
\hline 9 & $170^{*}$ & $180^{*}$ & +10 & $160^{*}$ & -10 & $170^{*}$ & 0 & 300 & +130 \\
\hline 10 & 310 & 310 & 0 & 320 & +10 & 400 & +90 & 450 & +140 \\
\hline 11 & 150 & 150 & 0 & 170 & +20 & $230^{*}$ & +80 & $230^{*}$ & +80 \\
\hline 12 & 160 & 150 & -10 & 160 & 0 & 160 & 0 & 170 & +10 \\
\hline 13 & 170 & 170 & 0 & 180 & +10 & 220 & +50 & $220^{*}$ & +50 \\
\hline 14 & 140 & 190 & +50 & 130 & -10 & 150 & +10 & 220 & +80 \\
\hline Mean & 134 & 134 & 0 & 139 & +4 & 161 & +27 & 236 & +101 \\
\hline SD & 66.8 & 71.2 & 15.7 & 71.8 & 13.4 & 89.9 & 40.3 & 87.8 & 70.8 \\
\hline SE & 17.8 & 19.0 & 4.2 & 19.2 & 3.6 & 24.0 & 10.8 & 23.5 & 18.9 \\
\hline \multicolumn{10}{|c|}{ Hearts maintained in medium containing $5 \times 10^{-6} \mathrm{M} \mathrm{T}_{3}$} \\
\hline 1 & 320 & 320 & $\mathbf{0}$ & 350 & +30 & 380 & +60 & 420 & +100 \\
\hline 2 & 90 & 100 & +10 & 150 & +60 & 230 & +140 & 290 & +200 \\
\hline 3 & $220^{*}$ & $220^{*}$ & 0 & 240 & +20 & 300 & +80 & $240^{*}$ & +20 \\
\hline 4 & 280 & 280 & 0 & 320 & +40 & 340 & +60 & 480 & +200 \\
\hline 5 & 80 & 90 & +10 & 110 & +30 & 140 & +60 & $150^{*}$ & +70 \\
\hline 6 & 120 & 130 & +10 & $110^{*}$ & -10 & $130^{*}$ & +10 & $180^{*}$ & +60 \\
\hline 7 & $230^{*}$ & $270^{*}$ & +40 & $210^{*}$ & -20 & $290^{*}$ & +60 & $390^{*}$ & +160 \\
\hline 8 & 110 & 110 & 0 & 120 & +10 & 120 & +10 & 90 & -20 \\
\hline 9 & 50 & 50 & 0 & $60^{*}$ & +10 & 70 & +20 & $250^{*}$ & +200 \\
\hline 10 & 130 & 130 & 0 & 140 & +10 & 170 & +40 & 220 & +90 \\
\hline 11 & 180 & 180 & 0 & 220 & +40 & 400 & +220 & 360 & +180 \\
\hline 12 & $100^{*}$ & $100^{*}$ & 0 & $140^{*}$ & +40 & 390 & +290 & $400^{*}$ & +300 \\
\hline 13 & $90^{*}$ & $90^{*}$ & 0 & $80^{*}$ & -10 & $100^{*}$ & $\begin{array}{l}10 \\
+10\end{array}$ & 180 & $\begin{array}{r}+90 \\
+90\end{array}$ \\
\hline 14 & 160 & 160 & 0 & 190 & +30 & 200 & +40 & 230 & +70 \\
\hline Mean & 154 & 159 & +5 & 174 & +20 & 233 & +79 & 277 & +123 \\
\hline SD & 81.0 & 83.0 & 10.9 & 86.0 & 22.9 & 115.9 & 83.4 & 115.7 & 86.4 \\
\hline $\mathrm{SE}$ & 21.7 & 22.2 & 2.9 & 23.0 & 6.1 & 31.0 & 22.3 & 30.9 & 23.1 \\
\hline
\end{tabular}

Abbreviations: NE, norepinephrine; $\mathrm{T}_{3}$, triiodothyronine.

* Arrhythmia present. 


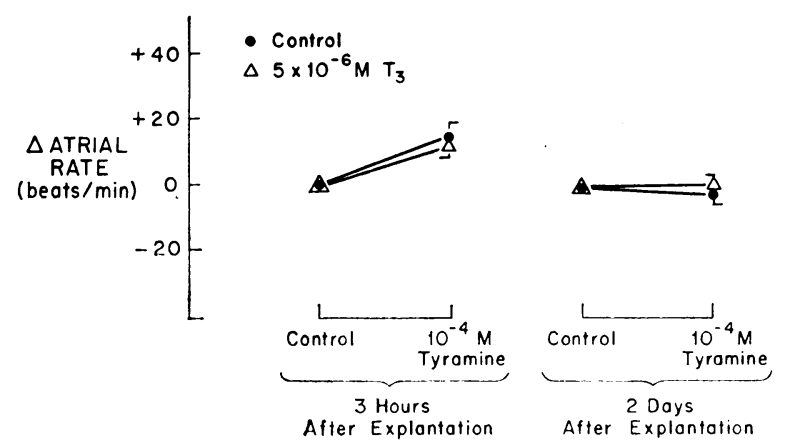

Figure 2 Response to tyramine of isolated hearts maintained for $3 \mathrm{hr}$ and for 2 days in the presence or absence of triiodothyronine $\left(\mathrm{T}_{3}\right)$. Symbols as in Fig. 1. Atrial rates increased significantly $(P<0.05)$ in both groups at $3 \mathrm{hr}$, but did not change at 2 days. Control and $T_{\text {:-treated hearts }}$ responded similarly.

not significantly different in the presence or absence of triiodothyronine. When norepinephrine was given in progressively increasing doses, tachycardia developed in all groups. The effect of norepinephrine was significantly greater for all groups at 2 days than at $2 \frac{1}{2}-3$ hr (Tables I and II) presumably because of the development of denervation hypersensitivity in the isolated organs.

The maximal increase in atrial rate (at $10^{-6}$ an norepinephrine) was similar in triiodothyronine-treated and control hearts. On the other hand, lower doses of norepinephrine raised the atrial rate to a much greater

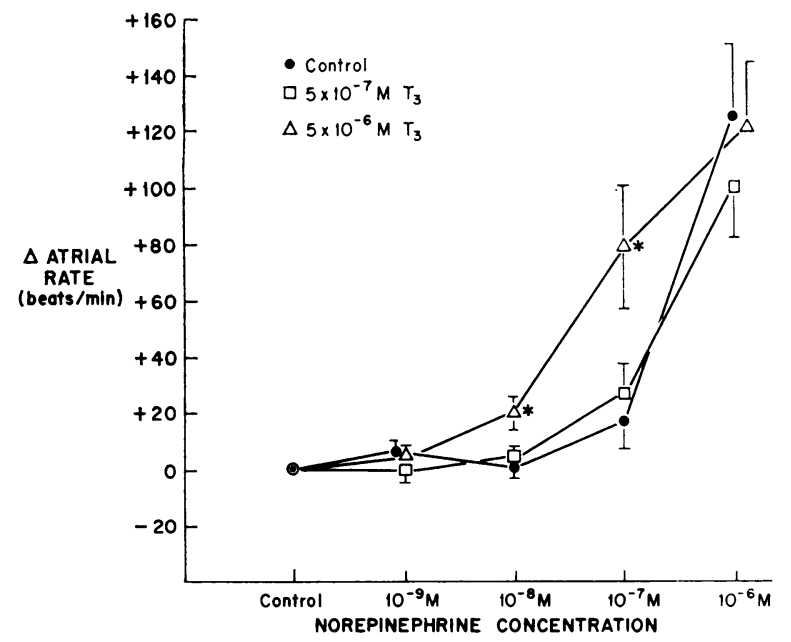

Figure 3 Dose-response curve of isolated hearts maintained for 2 days in the presence or absence of triiodothyronine $\left(\mathrm{T}_{3}\right)$, relating changes in spontaneous atrial rates to the concentration of norepinephrine. Symbols as in Fig. 1. *Significantly different from control hearts $(P<0.05$ by Student's $t$ test for unpaired samples). See Table II for absolute values of heart rate. extent in hearts exposed to the higher amounts of triiodothyronine than in control hearts or hearts exposed to the smaller concentration of triiodothyronine (Fig. 3). Norepinephrine in a dose of $10^{-8} \mathrm{M}$ raised the atrial rate by $20 \pm 6.1$ ( $\mathrm{SEM}$ ) beats $/ \mathrm{min}$ in hearts given $5 \times 10^{-6}$ ar triiodothyronine vs. $1 \pm 3.0$ beats $/ \mathrm{min}$ in control hearts $(P<0.02$ by Student's $t$ test for unpaired samples). With $10^{-7} \mathrm{M}$ norepinephrine, the rate rose by $79 \pm 22.3$ in treated hearts vs. $17 \pm 9.8$ in controls $(I<0.05)$. Thus, a shift to the left in the atrial closeresponse curve occurred as a result of exposure of the hearts for 2 days to high levels of thyroid hormone. Isolated ventricles responded to norepinephrine in less distinctive patterns than did atria, and increases in spontaneous rentricular rates were not significantly clifferent between the various groups.

Because both triiodothyronine and norepinephrine can alter cardiac rhythm as well as absolute beating rates, attention was directed to the incidence of abnormal rhythms. Both atrial and ventricular arrhythmias were more frequent in triiodothyronine-treated hearts than in controls. As shown in Fig. 4, as many as $40 \%$ of hearts exposed for 2 days to high concentrations of the hormone had abnormal rhythms even before norepinephrine was given. The addition of norepinephrine itself caused arrhythmias in still other hearts, even though regular rhythm had been present in the base line state. These norepinephrine-induced arrhythmias occurred in 2 of $28(14 \%)$ of control hearts, in 10 of $23(44 \%)$ of hearts treated for 2 days with $5 \times 10^{-7}$ M triiodothyronine $\left(P<0.01\right.$ by $\chi^{2}$ test $)$, and in 10 of 18 $(56 \%)$ of hearts given $5 \times 10^{-8}$ M triiodothyronine $(P<0.01)$. The arrhythmias that were induced in thyroid-treated hearts tended to appear at lower doses of norepinephrine than they did in control hearts (Fig. 5).

Because arrhythmias occurred more commonly in hearts exposed to thyroid hormones than in controls. it seemed possible that the faster atrial rates that developed in the "thyrotoxic" hearts after norepinephrine could be caused by the appearance of irregularly firing pacemakers rather than by a change in the spontaneous firing of a regular pacemaker. To test this possibility rates were analyzed in hearts that had retained the same basic rhythm during the control state and during exposure to $10^{-9}-10^{-7} \mathrm{M}$ norepinephrine. As is apparent in Fig. 6, significant differences were still apparent in the responses of the hearts exposed to high levels of triiodothyronine, even in the absence of arrhythmias.

When 2-day hearts were exposed to tyramine $\left(10^{-4}\right.$ $\left.10^{-3} \mathrm{M}\right)$ their beating rates did not change and no arrhythmias were induced. Results were identical for both triiodothyronine-treated and control hearts (Fig. 2). 


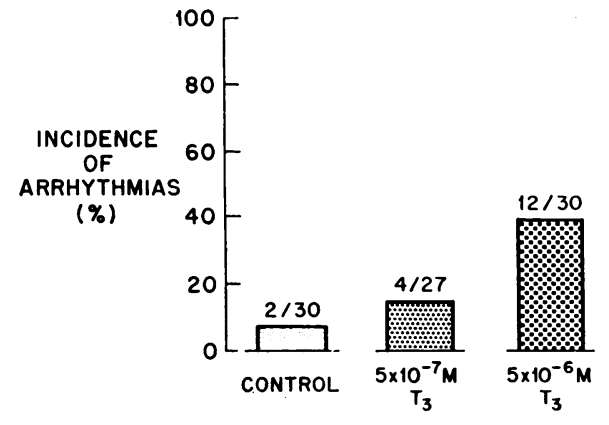

FIGURE 4 Incidence of arrhythmias (atrial and ventricular) before norepinephrine administration in hearts maintained for 2 days in the presence or absence of triiodothyronine $\left(T_{3}\right)$. Hearts treated with $5 \times 10^{-6} \mathrm{M} \mathrm{T}_{3}$ were significantly different from control hearts $\left(P<0.01\right.$ by $\chi^{2}$ test $)$.

\section{DISCUSSION}

The results of these experiments demonstrate that isolated hearts from late-fetal mice develop enhanced sensitivity to norepinephrine after prolonged exposure to triiodothyronine under precisely controlled conditions in vitro. The increased responsiveness is manifested by greater increases in atrial rate at submaximal concentrations of norepinephrine and by an increased incidence of norepinephrine-induced arrhythmias. Whether or not the inotropic response to norepinephrine is also altered under similar conditions cannot be discerned from the present experiments.

Several previous studies have suggested that hypersensitivity to catecholamines is a common feature of hyperthyroidism (18-21). On the other hand, more recent experiments have indicated that the heart rate response to graded doses of norepinephrine is no different after induction of hyperthyroidism in vivo (3-8). In these studies base line heart rates were significantly higher in hyperthyroid hearts than in controls. Furthermore, the data of Lee, Lee, and Yoo (22) and of Wurtman, Kopin, and Axelrod (23) and others suggest that hearts made thyrotoxic in vivo have elevated atrial concentrations of norepinephrine and are chronically exposed to higher base line levels of free catecholamines than are controls. Thus, no matter how carefully controlled the experiments may be, studies in which simple changes in beating rates are compared in hearts from normal and hyperthyroid animals must inevitably suffer from the fact that base line values are significantly different. There is no reason to suppose, for example. that a given increase in heart rate in a euthyroid heart has the same physiological meaning as the same absolute increased from a significantly higher base line in a thyrotoxic heart in which background catecholamine stimulation is already elevated. Rather, as Tenney (24) has emphasized in another context, abnormally high

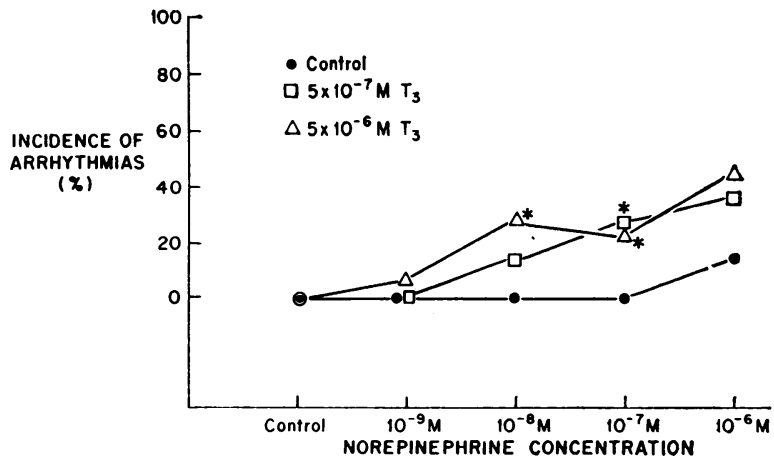

Figite 5 Dose-response curve of isolated hearts that were initially in regular rhythm after cultivation for 2 days in the presence or absence of triiodothyronine $\left(T_{:}\right)$, relating the incidence of norepinephrine-induced arrhythmias to the concentration of norepinephrine. Symbols as in Fig. 1. *Significantly different from control hearts $\left(P<0.05\right.$ by $\chi^{2}$ test $)$.

base line heart rates and/or partial "saturation" of receptor sites by high background levels of free catecholamines might well cause subsequent reactivity to exogenous catecholamines to appear artificially low.

In the present experiments, tests of sensitivity to norepinephrine were made 2 days after explanation of the hearts, at a time when base line heart rates were similar in all groups and when responsiveness to tyramine had been lost. At that time, no group contained any measurable catecholamines, suggesting, as did the absence of response to tyramine, that treated and control hearts had no endogenous catecholamines or base line sympathetic activity.

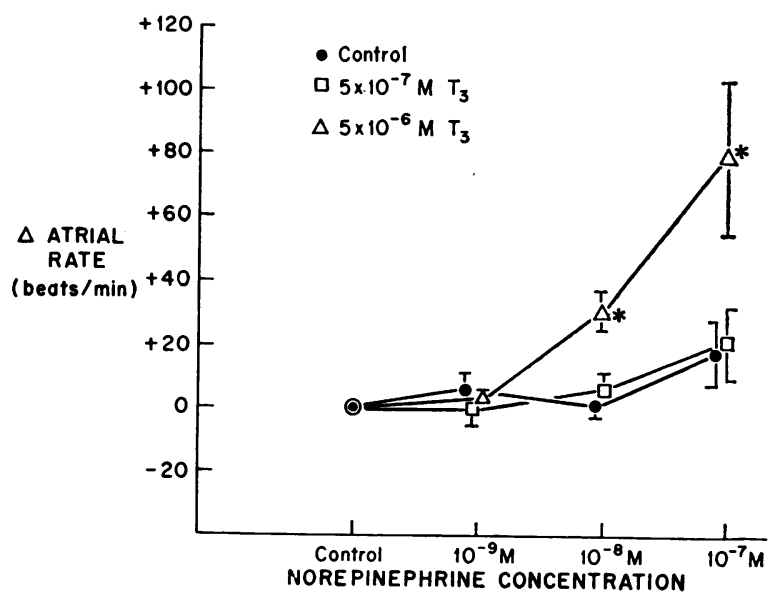

Figure 6 Dose-response curve of isolated hearts maintained for 2 days in the presence or absence of triiodothyronine $\left(\mathrm{T}_{3}\right)$, relating changes in spontaneous atrial rates of hearts that remained in regular rhythm to the concentration of norepinephrine. Symbols as in Fig. 1. *Significantly different from control hearts $(P<0.05$ by Student's $t$ test for unpaired samples). 
Most evidence suggests that the cardiac effects of thyroid hormones, like most of their other actions, are slow to appear $(9-11,13)$. Some investigators, however, have suggested that triiodothyronine may alter myocardial properties acutely $(25,26)$. Cultures of isolated, dispersed myocardial cells develop an immediate tachycardia when the hormone is added to the medium (25), unlike the delayed augmentation of rate that occurs in cultures of intact hearts (13). It seems likely that the atypical responsiveness of isolated cells may be a consequence of the unavoidable membrane and ultrastructural damage incurred by the cells during the enzymatic digestion and mechanical agitation employed in the dispersion process (27) and does not represent a normal physiological action.

Consistent with the usual physiological effects of triiodothyronine, changes observed in the present study were slow to develop. No differences between control and treated hearts were apparent for over $3 \mathrm{hr}$ after exposure to the hormone. This suggests that the effects observed at 2 days were not a nonspecific or toxic action of the chemical used (22), but rather, were due to the characteristic delayed action of the hormone. Efforts to repeat the experiments after 4 or more days of culture were abandoned because by that time most of the hearts exposed to triiodothyronine were beating irregularíy and at a rate significantly different from controls (13), making valid comparisons of absolute changes in rate impossible.

At 2 days, responses of heart rate and rhythm to submaximal doses of norepinephrine were markedly altered when high concentrations $\left(5 \times 10^{-6} \mathrm{M}\right)$ of triiodothyronine had been added to the culture medium. When lower concentrations $\left(5 \times 10^{-7} \mathrm{M}\right)$ of the hormone were used the incidence of norepinephrine-induced arrhythmias remained increased, but there was no significant shift from control in the heart rate response. The concentrations of triiodothyronine that were used were chosen because they are well beneath the levels that cause "toxic" manifestations of excessive thyroid administration such as uncoupling of oxidative phosphorylation (10), yet are high enough to cause "hyperthyroid" manifestations (13). Because the heart actively metabolizes thyroid hormones (28), and because triiodothyronine adsorbs to glass, metal, etc., the net concentration in the medium over the 2 day culture period must inevitably have been lower even than the nominal concentrations.

It is always possible to argue, of course, that differences in results obtained in the present system and in vivo might have occurred simply because fetal hearts were used rather than adult hearts or because the present system is unphysiological. Indeed, hearts maintained in organ culture are not "normal," as attested by the wide range of spontaneous heart rates observed in this and previous studies (12). Nevertheless, the beating rate for each heart remains unchanged, and appropriate responsiveness to catecholamines and acetylcholine persists throughout the duration of cultivation (12. 13). Thus, whatever their deviations from "normal" characteristics in vivo, fetal mouse hearts in organ culture do beat and function in a stable manner for several days. Any unphysiological characteristics they may possess are shared equally by control and experimental organs. Thus, it seems reasonable to conclude that at least one kind of functioning myocardial tissue gradually develops supersensitivity to norepinephrine during prolonged exposure to elevated levels of triiodothyronine. The change occurs under precisely controlled conditions in which secondary changes in neural and humoral factors are eliminated. The cellular mechanism by which supersensitivity might develop remains obscure, and should provide a fruitful field for future investigation.

\section{ACKNOWLEDGMENTS}

This work was supported in part by grants from the American Heart Association and the National Heart and Lung Institute (HL 14706).

\section{REFERENCES}

1. Grossman, W., N. I. Robin, L. W. Johnson, H. L. Brooks, H. A. Selenkow, and L. Dexter. 1971. The enhanced myocardial contractility of thyrotoxicosis. Role of the beta adrenergic receptor. Ann. Intcrn. Med. 74: 869.

2. Levey, G. S. 1971. Catecholamine sensitivity, thyroid hormone and the heart. A reevaluation. Am. J. Mcd. 50: 413 .

3. van der Schoot, J. B., and N. C. Moran. 1965. An experimental evaluation of the reputed influence of thyroxin on the cardiovascular effects of catecholamines. J. Pharmacol. Exp. Ther. 149: 336.

4. Margolius, H. S., and T. E. Gaffney. 1965. The effects of injected norepinephrine and sympathetic nerve stimulation in hypothyroid and hyperthyroid dogs. J. Pharmacol. Exp. Ther. 149: 329.

5. Cravey, G. M., and J. S. Gravenstein. 1965. The effect of thyroxin, corticosteroids, and epinephrine on atrial rate. J. Pharmacol. Exp. Ther. 148: 75.

6. Cairoli, V. J., and J. R. Crout. 1967. Role of the autonomic nervous system in the resting tachycardia of experimental hyperthyroidism. J. Pharmacol. Exp. Ther. $158: 55$.

7. Aoki, V. S., W. R. Wilson, E. O. Theilen, W. W. Lukensmeyer, and P. E. Leaverton. 1967. The effects of triiodothyronine on hemodynamic responses to epinephrine and norepinephrine in man. J. Pharmacol. Exp. Ther. $157: 62$.

8. Anton, A. H.; and J. S. Gravenstein. 1970. Studies on thyroid-catecholamine interactions in the isolated rabbit heart. Eur. J. Pharmacol. 10: 311.

9. Markowitz, C., and W. M. Yater. 1932. Response of explanted cardiac muscle to thyroxine. Am. J. Physiol. 100: 162 . 
10. Tata, J. R. 1964. Biological action of thyroid hormones at the cellular and molecular levels. In Actions of Hormones on Molecular Processes. G. Litwack, and D. Kritchevsky, editors. John Wiley \& Sons, Inc., New York. 58.

11. Skelton, C. L., F. E. Karch, and K. Wildenthal. 1972. Lack of acute effects of thyroid hormones on ventricular contractility. Am. J. Physiol. In press.

12. Wildenthal, K. 1971. Long-term maintenance of spontaneously beating mouse hearts in organ culture. $J$. Appl. Physiol. 30: 153.

13. Wildenthal, K. 1971. Responses to cardioactive drugs of fetal mouse hearts maintained in organ culture. $\mathrm{Am}$. J. Physiol. 221 : 238.

14. Morgan, J. F., H. J. Morton, and R. C. Parker. 1950. Nutrition of animal cells in tissue culture. I. Initial studies on a synthetic medium. Proc. Soc. Exp. Biol. Med. $73: 1$.

15. Wildenthal, K., D. Harrison, G. H. Templeton, and W. C. Reardon. 1972. A method for measuring the contractions of small hearts in organ culture. Cardiovasc. Res. In press.

16. Zaimis, E. 1968. Vasopressor drugs and catecholamines. Anesthesiology. 29: 732.

17. Shore, P. A. 1962. Release of serotonin and catecholamines by drugs. Pharmacol. Rev. 14: 531.

18. McDonald, C. H., W. L. Shepheard, M. F. Green, and A. F. DeGroat. 1935. Response of the hyperthyroid heart to epinephrine. Am. J. Physiol. 112: 227.

19. Wise, B., and H. E. Hoff. 1938. The effect of auto- nomic hormones on the thyrotoxic heart. J. Pharmacol. Exp. Ther. $64: 217$.

20. Brewster, W. R., Jr., J. P. Isaacs, P. F. Osgood, and T. L. King. 1956. The hemodynamic and metabolic interrelationships in the activity of epinephrine, norepinephrine, and the thyroid hormones Circulation. 13: 1.

21. Harrison, T. S. 1964. Adrenal medullary and thyroid relationships. Physiol. Rev. 44: 161.

22. Lee, W. C., C. Y. Lee. and C. S. Yoo. 1965. Effects of treatment with thyroxine on the noradrenaline content of the rabbit heart. Br. J. Pharmacol. 25: 651 .

23. Wurtman, R. J., I. J. Kopin, and J. Axelrod. 1963. Thyroid function and the cardiac disposition of catecholamines. Endocrinology. 73: 63.

24. Tenney, S. M. 1956. Sympatho-adrenal stimulation by carbon dioxide and the inhibitory effect of carbonic acid on epinephrine response. Am. J. Physiol. 187: 341.

25. Wollenberger, A. 1964. Akute Wirkung von Trijodthyronin auf die Spontanrhythmik isolierter, in vitro kultivierter Herzzellen. Naunyn-Schmiedebergs Arch. Pharmacol. Exp. Pathol. 249 : 288.

26. Baird, J. R. C., and B. A. Spilker. 1970. Inotropic effects of thyroxine and related compounds on guineapig left atria in vitro. Br. J. Pharmacol. 40: 526.

27. Wollenberger, A. 1964. Rhythmic and arrhythmic contractile activity of single myocardial cells cultured in vitro. Circ. Res. 15(Suppl. II) : 184.

28. Rabinowitz, J. L., and E. S. Hercker. 1971. Thyroxine: conversion to triiodothyronine by isolated perfused rat heart. Science (Wash. D. C.). 173: 1242. 